\title{
The Smartphone Users Behavior for Mcommerce-An Empirical Study
}

\author{
Chiang-nan Chao \& Yanni Ping, Ph.D. \\ Peter Tobin College of Business, \\ St. John's University, New York, USA \\ Yingchuan Wang \\ BNP Paribas, Hong Kong
}

\begin{abstract}
Smartphone has become an important phenomenon in the retail industry in the past 22 years. Since Apple introduced its first generation of iPhone in 2007, smartphone has penetrated about $70 \%$ of American population. American adults spend more time on their smartphones, do more shopping than on their personal computers. As a result, mobile commerce has emerged from a supplement to electronic commerce and has become a heavily weighted sector in the electronic retail businesses. In next few years, US mcommerce will be outpaced other ecommerce. Marketers need to better understand this market segment, and better target smartphone users through programmatic advertising, particularly when they find the phone users are interested in particular products they browse. This study focuses on several aspects of the phone users' behavior. The results of this research may offer a glimpse for researchers and marketers alike.
\end{abstract}

Keywords: smartphone users, mcommerce, ecommerce.

\section{Introduction}

Smartphone has penetrated about $70 \%$ of the US population (eMarketer, 2018a). Smartphone IP traffic will exceed PC traffic, as PCs traffic accounted for 41 percent of the total IP traffic, but by 2022 PCs traffic will shrink to only 19 percent of the total IP traffic; smartphones accounted for only 18 percent in 2017, will increase to 44 percent of the total IP traffic in the same six-year period (Cisco VNI report, 2018).

US retail mcommerce sales increased about $23 \%$ in 2018 to $\$ 133$ billion, as compared to that of 2017 . That translates to $27 \%$ of the total retail ecommerce sales. The bulk of US retail mcommerce growth is in line with rapid growth of smartphone sales, and the average adult daily usage of smart phone had outpaced the uses of personal computers for the first time a year earlier (eMarketer, 2018b).

Fifth-generation (5G) build up is underway and will increase the mobile IP traffic exceeded fourth generation (4G) and third-generation $(3 \mathrm{G})$ traffic in the next couple of years, as the $4 \mathrm{G}$ connection already has penetrated $94 \%$ of the North America (eMarketer, 2018b), while the mobile traffic accounted for about $9 \%$ of the total traffic.

The phenomenon of rapid growth of smartphone usage and mobile traffic become interest for the researchers and practitioners. This empirical study intends to focus on the smartphone user behavior and hope to offer some glimpse insights for marketer in their strategic thinking.

\section{Review of literature}

The global market for smartphones has increased rapidly in the past years that make it easier for the users to browse on the web for a variety of products. Figure 1 presents the global smartphone shipment in the past years. At the meantime, data traffic via mobile devices have grown by leaps and bounds. Figure 2 illustrates the global mobile traffic growth in the past years, measured by petabytes per month (a petabyte is 1,000,000 of gigabyte) 
Figure 1: Global smartphone shipment, 2009-2022, in mil of units.

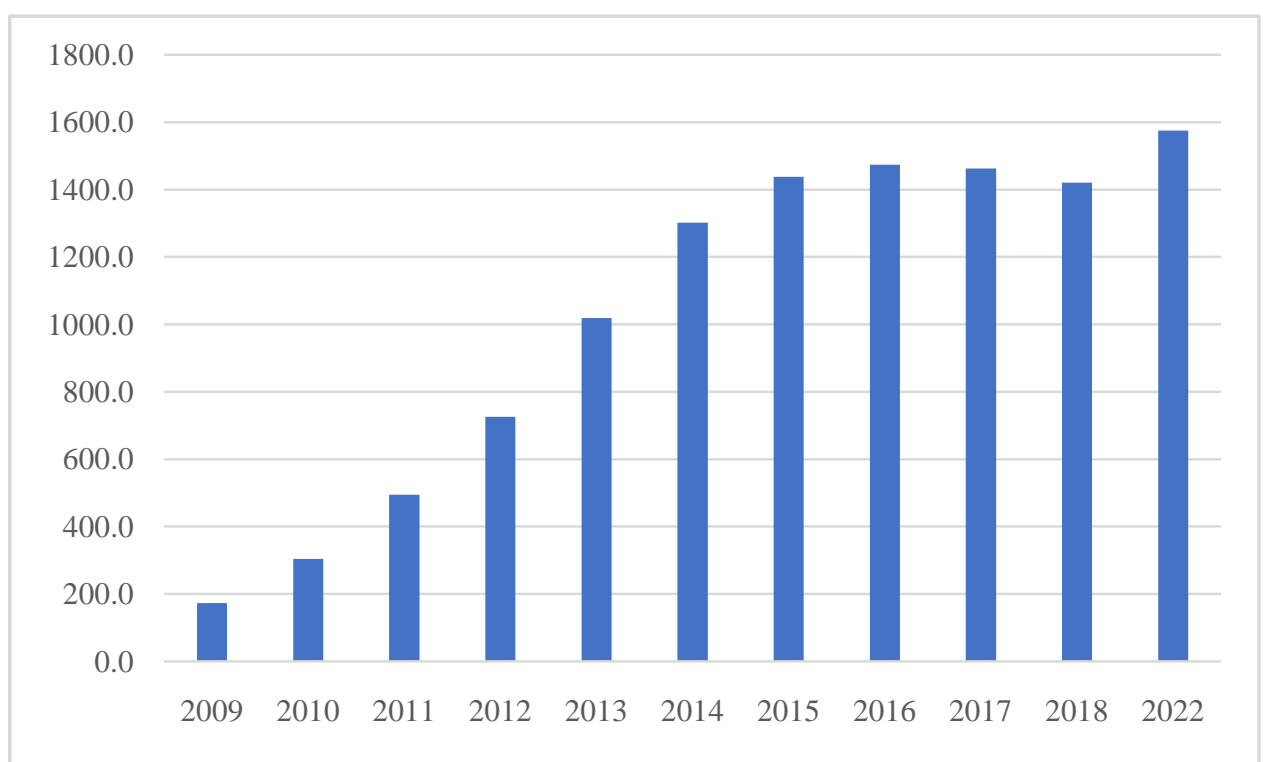

forecast/

Sources: Statista, 2018, https://www.statista.com/statistics/263441/global-smartphone-shipments-

Figure 2: Global mobile traffic growth, petabytes per month

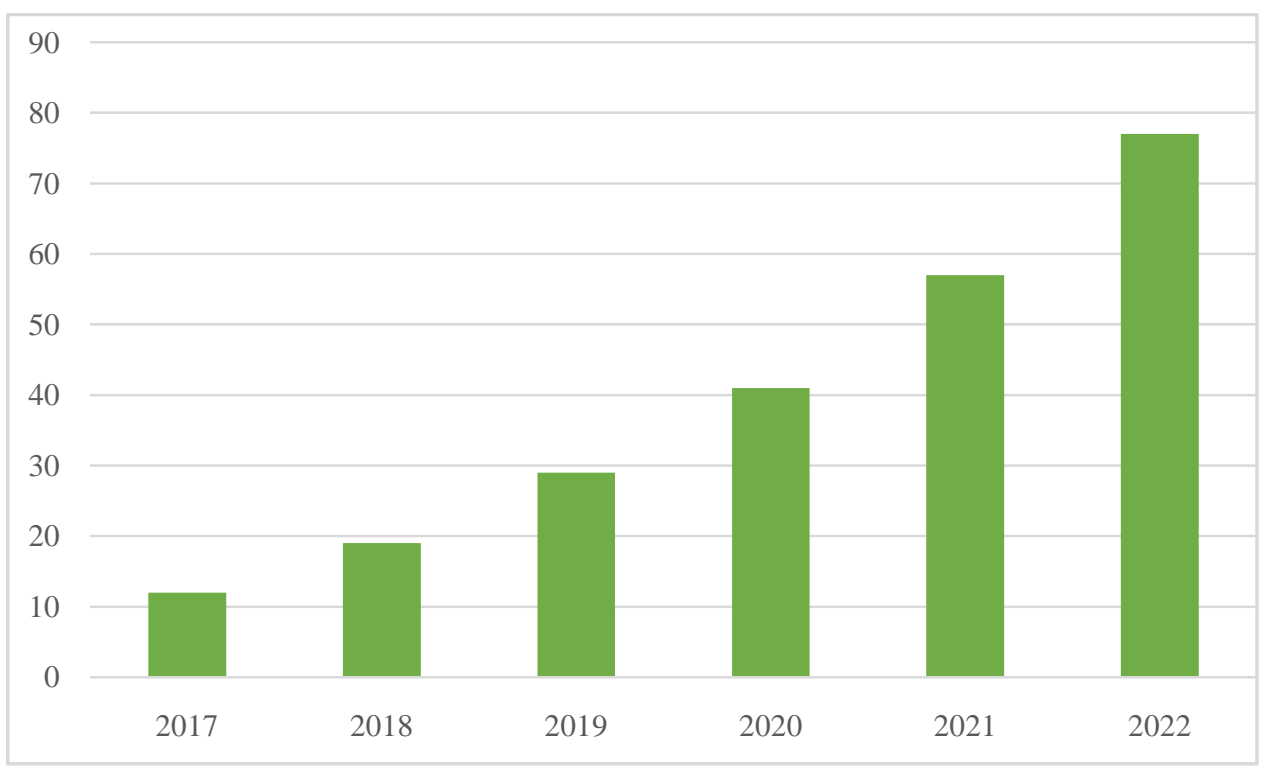

Source: Cisco VNI, 2018. https://www.cisco.com/c/en/us/solutions/collateral/service-provider/visualnetworking-index-vni/white-paper-c11-741490.html

During the past years, adults have spent more time on their smartphones than on the personal computers, and this trend will continue. According to eMarketer, by 2019, adults will spend more time on their smartphone than on TV. Figure 3 illustrates the pattern of adult time spent on their smartphone. 
Figure 3: Time spent per adult user per day on the smartphones, USA

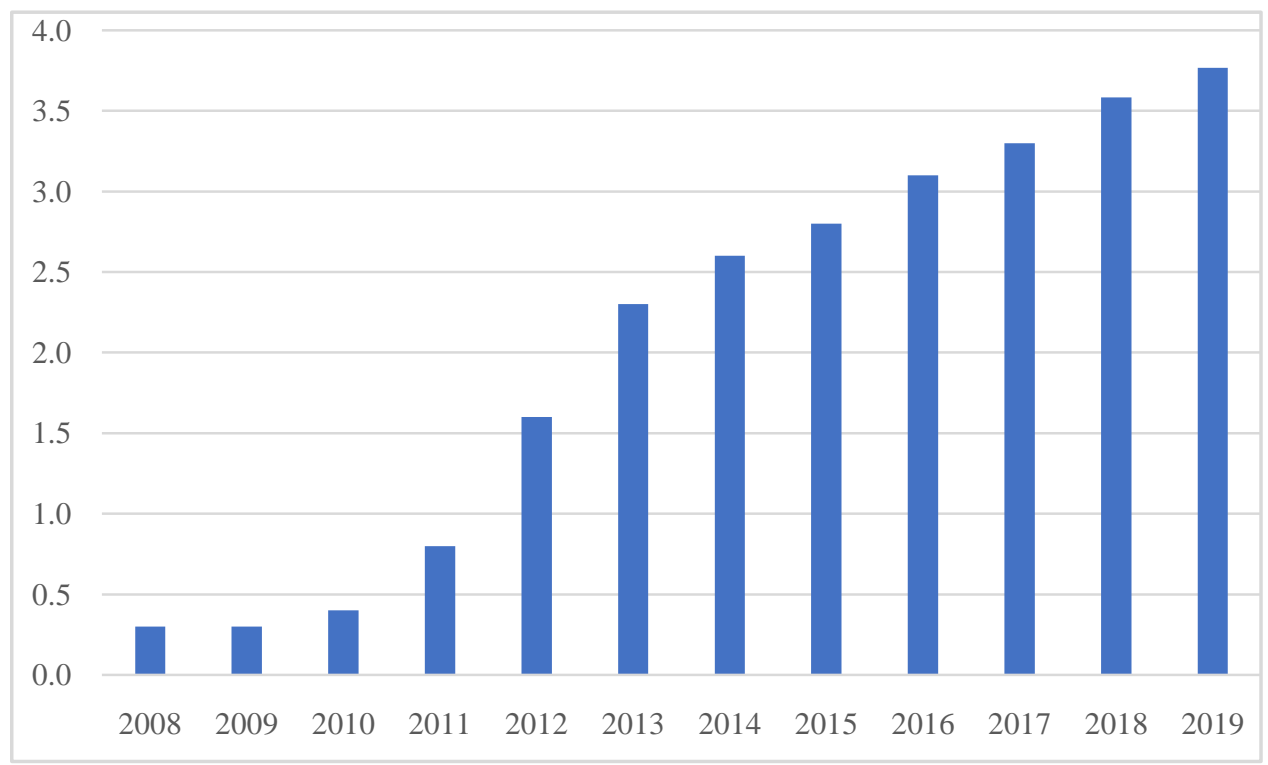

Source: emarketer, 2018b, https://www.emarketer.com/content/mobile-time-spent-2018.

Fulgoni and Lipsman (2016) studied future mobile commerce. They discovered that marketers who looked only at the bottom-line effects of mobile shopper activities on retailing were missing important clues about the future. "Mobile still is not a significant channel in driving actual purchases," observe comScore, Inc. CEO, Gian M. Fulgoni, and VP of Marketing and Insights, Andrew Lipsman. Yet, "data from Deloitte forecast that in 2016, mobile will have influenced $\$ 689$ billion in U.S. in-store sales, up from just $\$ 158$ billion in 2012-a compound annual growth rate of 45 percent. These mobile-influenced sales figures account for in-store product purchases for which a mobile device aided in the shopping experience". Figure 4 presents the m-commerce growth in the past years.

Figure 4: retail m-commerce sales in US\$ bil.

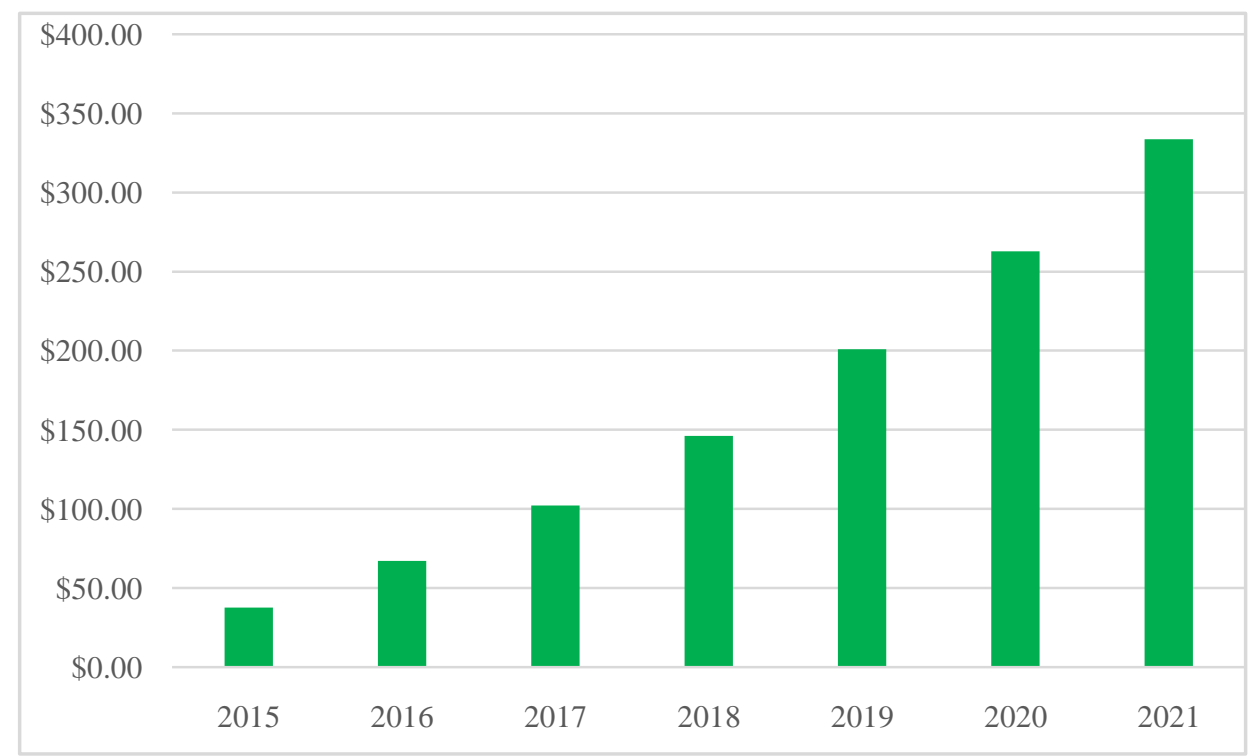

Source: eMarketer, 2018. http://zugara.com/mcommerce-only-2-percent-of-total-retail-sales-by-2018how-will-mobile-influence-in-store-retail-experience

According to a survey conducted by Clutch, a B2B research firm, almost seven in 10 mcommerce app users in the US access the apps to receive deals and offers. Nearly as many said they appreciate them for the flexibility to buy at any time. New data from The Integer Group illustrates the rapid shift of consumer behavior over the past few years. In surveys conducted in 2012 and 2016, the percentage of internet users who make purchases via mobile device rose substantially, from just a quarter in 2012 to nearly two-thirds last year (eMarketer, 2017). 
Faulds, et al discovered that the use of mobile devices by consumers and the accompanying response by retailers is rapidly revolutionizing the retail environment. In the past, retailers have focused primarily on the outcome (to purchase or not to purchase) of the consumer decision process, but now mobile technologies give retailers the opportunity to more actively influence the entire consumer decision-making processes. The increasing use of mobile devices by consumers makes shopping a continuous rather than discrete activity that requires retailers to engage with their customers at critical touch points of the decision process to provide a more customer-centric experience. This change in focus from the decision outcome to the decision process signifies an important paradigm shift for the retailing industry. After an extensive review of the literature, we identify four pillars that form the foundation for the mobile shopping revolution and represent the essential ways and means through which retailers can engage with consumers during the decision process. We also discuss the different areas in which the pillars can enable retailers to achieve a sustainable competitive advantage in the mobile shopping era (Faulds, et al 2018).

Yang and Lee (2017) focused on distinguishing mobile interactivity (m-interactivity) from interactivity via fixed broadband Internet (e-interactivity). They explored several comprehensive dimensions of interactivity and identify four key dimensions of m-interactivity by conducting both exploratory factor analysis and confirmatory factor analysis. They established the influence of m-interactivity on the consumer response variables of enjoyment, satisfaction, and loyalty, as well as the relationships among them.

Stewart and Cunningham (2017), and Ford (2017) studied the mobile form of marketing and revealed that this platform offered consumers unique experiences and a diverse selection of content. They discovered that with so many platforms at consumers' disposal, advertisers struggle to track the usage of each platform and the response to advertising on it. Marketers aim to reach, resonate with, and evoke a reaction from the right audience at the right time, which increases the importance of multiplatform metrics. They offered further theoretical explanations and managerial implications.

Hsu and Yeh (2018) find four critical success factors that influence M-commerce adoption: perceived ease of use, perceived usefulness, value-added and service functionality. In addition, these factors were identified as the cause and effect factors. The results of this study are presented to M-commerce service providers' in facilitating the development of wireless services. Lin, et al (2017) explored the determinants of consumers' use of mobile commerce, and their act of payment. They found that security concerns and privacy concerns are the most important factors.

Raphaeli, et al (2017) analyzed online consumer behavior in mobile and PC devices. They investigated and compared online consumer behavior on an e-retailer website in mobile versus PC devices, through the application of a web usage mining approach on clickstream data recorded in server-side log files. Online consumer behavior is characterized through both engagement measures and the discovery of common sequences of navigation patterns, using an innovative approach that combines footstep graph visualization with sequential association rule mining. They found that sessions conducted through mobile devices are more likely to consist of task-oriented behavior whereas sessions conducted through PC devices are characterized by a more exploration-oriented browsing behavior. They also found that certain sequence rules were associated with an increased likelihood of purchase in both mobile and PC sessions.

Chao (2017) investigated mobile commerce, which has emerged as an important sector in retail businesses, as US smartphones have penetrated near $80 \%$ of the population in 2017. The average adult daily usage of smart phone outpaced personal computers for the first time, and the users do more commerce on their smartphones than on their personal computers. As predicted by eMarketer US mcommerce will be a half of the total ecommerce by 2020. As a result, marketers have spent advertisement on smartphones. The marketers realize that they can better target smartphone users through programmatic advertising, particularly when they find the phone users are interested products they browse. This research, through an empirical survey, focuses on the effectiveness of mobile marketing. The research results confirm this marketing trend and provide some useful insights for marketers in their future marketing endeavors.

The review of literature tenders a wide range of aspects for mobile commerce. While this study intends to focus only on the fundamental issues: the limited aspects of smartphone user behavior, and comparisons of computer and smartphone usages. The objective of the study intends to provide some insights to marketers that would help them better reach their customers.

\section{Methodology}

This study focuses on smartphone user behaviors. A survey questionnaire was designed to investigate the features that were most important for the advertisers. 


\subsection{Variable Selection}

The variables that were selected are based on the literature review. Twelve research variables were identified and presented below. The respondents were asked to give their own experience on mobile phone uses and compare with the computer uses.

The following user behavior variables were evaluated:

1. How important to use smartphone for playing games?

2. How important to use smartphone for class work?

3. How important to use smartphone for watching movies and videos?

4. How important to use smartphone for news and sports?

5. How important to use smartphone for talking?

6. How important to make comparative shopping on smartphone?

7. How important to browse shopping apps on smartphone?

\subsection{Sampling, Hypotheses, and Tests of Hypotheses}

The targeted sample respondents were college students in a large university in the northeast of the U.S. One-page survey questionnaires were distributed online over past semesters to target respondents, specifically with the aim of obtaining the opinions of the respondents who are often exposed to both traditional and digital advertising. The null hypotheses for this study stated:

$H_{1}$ There is no significant difference in using smartphone for playing games vs on game gadgets or televisions.

$\mathrm{H}_{2}$ There is no significant difference in using smartphone for class work vs on computers or in classrooms.

$\mathrm{H}_{3}$ There is no significant difference in using smartphone for watching movies and videos vs watching movies on television or go to movie theaters.

$\mathrm{H}_{4}$ There is no significant difference in using smartphone for finding news and sports info vs other means for gathering info.

$\mathrm{H}_{5}$ There is no significant difference in using smartphone for talking vs other means for talking, i.e. traditional landline phones.

$H_{6}$ There is no significant difference in using smartphone for comparative shopping.

$\mathrm{H}_{7}$ There is no significant difference in using smartphone for browsing apps for shopping?

The alternative hypotheses state: there is significant relationship between the respondents' views of mobile media advertising and computer/laptop advertising over these selected variables.

One sample Student's $t$-test is used to test the hypotheses. A $t$-test is any statistical hypothesis test in which the test statistic follows a Student's $t$ distribution if the null hypothesis is supported. It is most commonly applied when the test statistic would follow a normal distribution if the value of a scaling term in the test statistic is known. The one sample Student's $t$-test requires that the dependent variable follow a normal distribution. When the number of subjects in the experimental group is 30 or more, the central limit theorem shows a normal distribution can be assumed. If the number of subjects is less than 30, the researcher should plot the results and examine whether they appear to follow a normal distribution. If the distribution appears to be non-normal, and/or if the number of test cases is significantly less than 30, then a one sample median test, which does not require a normal distribution, should be used to test the hypothesis (Conover, 1980; Davis and Cosenza, 1985; Hamburg, 1977; $\operatorname{SPSS}^{\mathrm{X}}$, 2002; Wikipedia, 2012). Five percent of the $t$ Tests one tailed probability level was selected to signify the differences between preferences. When the scaling term is unknown and is replaced by an estimate based on the data, the test statistic (under certain conditions) follows a Student's $t$ distribution. The estimate value for testing hypotheses in this study is 3 , which is neutral.

\section{Results}

One thousand two hundred questionnaires were distributed college students and staffs in a large university in the northeast of the U.S., of which three hundred ninety-three were returned and usable. This represents roughly 33 percent response rate. The following table presents the background information of these respondents, including gender and income. 
Table 1. Background Information of the Respondents

\begin{tabular}{|c|c|c|}
\hline \multirow[b]{4}{*}{ Age } & $<18$ & 1.2 \\
\hline & $19-35$ & 94.9 \\
\hline & $36-50$ & 3.4 \\
\hline & $>50$ & 0.5 \\
\hline \multirow[b]{2}{*}{ Gender } & male & 53.2 \\
\hline & female & 46.8 \\
\hline \multirow{4}{*}{$\begin{array}{l}\text { Family } \\
\text { income in } \\
\text { USD }\end{array}$} & $<35 \mathrm{k}$ & 16.2 \\
\hline & $35-50 \mathrm{k}$ & 21.8 \\
\hline & $50-75 \mathrm{k}$ & 21.5 \\
\hline & $>75 \mathrm{k}$ & 40.5 \\
\hline \multirow[b]{2}{*}{ Education } & college & 91.9 \\
\hline & graduate & 8.1 \\
\hline \multirow{2}{*}{$\begin{array}{l}\text { Marital } \\
\text { Status }\end{array}$} & married & 23.2 \\
\hline & single & 76.8 \\
\hline \multirow{2}{*}{$\begin{array}{l}\text { Have a } \\
\text { smartphone }\end{array}$} & yes & 95.4 \\
\hline & no & 4.6 \\
\hline
\end{tabular}

Source: Original

Overall, the means of computer internet advertising are higher than those of smartphone advertising. Table 2 shows the Marginal Homogeneity Test results. It indicates that only one of paired variables test result shows significance levels less than 5\% (highlighted in bold). Therefore, one hypothesis where there are significant differences between the respondents' views of smartphone advertising versus computer internet advertising messages is rejected. The other 11 paired variables test results show significance levels more than 5\%. Therefore, these hypotheses are accepted: for these promotional elements there are no significant differences in the respondents' awareness based on smartphone advertising messages and the computer internet advertising messages.

Table 2: One-Sample t-Test Results, test value=3, neutral, degree of freedom=392

\begin{tabular}{|c|c|c|c|}
\hline & $t$ & $d f$ & Sig. \\
\hline 1. How important to use smartphone for playing games? & -18.6 & 392 & 0.000 \\
\hline 2. How important to use smartphone for class work? & 18.04 & 392 & 0.000 \\
\hline $\begin{array}{l}\text { 3. How important to use smartphone for watching movies and } \\
\text { videos? }\end{array}$ & 12.54 & 392 & 0.000 \\
\hline 4. How important to use smartphone for news and sports? & -9.99 & 392 & 0.000 \\
\hline 5. How important to use smartphone for talking? & -7.46 & 392 & 0.000 \\
\hline 6. How important to make comparative shopping on smartphone? & -3.91 & 392 & $\mathbf{0 . 0 0 0}$ \\
\hline 7. How important to browse shopping apps on smartphone? & -1.67 & 392 & 0.097 \\
\hline
\end{tabular}

\section{Managerial implications and recommendations}

The mean differences as compared to the test value of 3 which is neutral tell the researchers how relatively important of these variables. The results show that seven variables have significant levels less than 5\%, and these corresponding hypotheses are rejected. These variables are How important to use smartphone for playing games? How important to use smartphone for class work? How important to use smartphone for watching movies and videos? How important to use smartphone for news and sports? How important to use smartphone for talking? How important to make comparative shopping on smartphone? The rejections of these hypotheses indicate the significant differences exist in using smartphone as compared to other means.

One variable, test result shows significant level of $35.5 \%$ in How important to browse shopping apps on smartphone? therefore this hypothesis is accepted, as there is no difference.

\section{Limitations and future research}

The academic research that focuses on comparisons between computer internet and smartphone user behavior is limited, and the application and use of smartphone is evolving, as the time that smartphone users is picking up as compared to computers and other means, i.e. TV, radio, and printed media. It may take some years before significant 
research publications are available. As a preliminary and exploratory research, this study has provided if only limited glimpses of some fundamental aspects of smartphone usages.

Further in-depth research should delve more into the factors and elements that predict the effectiveness and efficiency of computers versus smartphone. Would consumers eventually prefer more smartphone shopping in the future? Does the younger generation differ from the older generation since younger people spend more time on their smartphones? As some of the respondents commented, they find using the smartphone enable them to handily obtain products and/or service related information. These issues should also be addressed in future research.

\section{References}

Chao, C. (2017). Emergence Impacts of Mobile Commerce: An Exploratory Study, Journal of Management and Strategy, Volume 8, No. 2, pp. 63-70.

Cisco, (2018). Virtual Network Index Report. Retrieve from https://www.cisco.com/c/en/us/solutions/collateral/service-provider/visual-networking-index-vni/white-paperc11-741490.html

Conover, W. J. (1980). Practical Nonparametric Statistics, 2nd ed., New York: John Wiley \& Sons, pp. 213-337 \& 344384.

Davis, D., \& Cosenza R. M. (1985). Business Research for Decision Making. Boston: Kent Publishing.

eMarketer, (2017), Source: Source: http://www.emarketer.com/Article/Mobile-Account-More-than-Half-of-Digital-AdSpending-2015/1012930

eMarketer, (2018a). https://www.emarketer.com/Chart/US-Smartphone-User-Penetration-by-Age-2018-of-populationeach-group $/ 219283$

eMarketer (2018b). Retrieved from https://www.emarketer.com/content/the-future-of-retail-in-2019

Faulds, D. J., Mangold, W. G., Raju, P.S., \& Valsalan, S (2018). The mobile shopping revolution: Redefining the consumer decision process, Business Horizons, Volume 61, Issue 2, March-April 2018, pp. 323-338.

Fulgoni, G. M. \& Lipsman, A. (2016). The Future of Retail Is Mobile, Journal of Advertising Research, June 56 (4), pp. 346-351; DOI: 10.2501/JAR-2016-041

Hamburg, M. (1977). Statistical Analysis for Decision Making. San Diego: Harcourt.

Holmes, A. \& Byrne, A. (2014). Mobile shopping behaviour: insights into attitudes, shopping process involvement and location, International Journal of Retail \& Distribution Management, Vol 42, Iss 1, pp. 25-39.

IBM SPSS Exact Tests, SPSS Inc. 2010.

Hsu, C. W., \& Yeh, C. C. (2018). Understanding the critical factors for successful M-commerce adoption, International Journal of Mobile Communications, 2018 Vol.16, No.1, pp.50 - 62

Lin, W. R., Wang, Y. H. \& Shih, K. H. (2017). Understanding consumer adoption of mobile commerce and payment behavior: an empirical analysis. International Journal of Mobile Communications, Vol.15, No.6, pp.628 - 654. DOI: 10.1504/IJMC.2017.10005646

Raphaeli, O., Goldstein, A., and Fink, L. (2017). Analyzing online consumer behavior in mobile and PC devices: A novel web usage mining approach, Electronic Commerce Research and Applications, Vol. 26, NovemberDecember, pp. 1-12. https://doi.org/10.1016/j.elerap.2017.09.003

Statista, 2018. https://www.statista.com/statistics/263441/global-smartphone-shipments-forecast/

Stewart, K \& Cunningham, I. (2017). Examining Consumers' Multiplatform Usage and Its Contribution to Their Trust in Advertising--The Impact of the Device on Platform-Use Frequency and Trust in Advertising across Platforms, Journal of Advertising Research, Vol. 57, Iss. 3, 1 September 2017. DOI: 10.2501/JAR-2017-003.

Yang, S. \& Lee, Y. J. (2017). The Dimensions of M-Interactivity and Their Impacts in the Mobile Commerce Contex, International Journal of Electronic Commerce, Volume 21, Number 4, pp. 548-571

Chiang-nan Chao, a Professor of Management. His publications can be found in Journal of World Business, the Journal of Supply Chain Management, the International Journal of Physical Distribution and Logistics Management, the Journal of Strategic Marketing, the Journal of Education for Business, the Industrial Marketing Management, Organizations and People, Journal of Teaching in International Business, etc. 